\title{
KAJIAN BALOK BETON STYROFOAM RINGAN DENGAN TULANGAN MENYEBAR
}

\author{
Arusmalem Ginting \\ Dosen Tetap, Jurusan Teknik Sipil, Universitas Janabadra \\ Jl. Tentara Rakyat Mataram No. , Yogyakarta \\ E-mail : agintm@yahoo.com
}

\begin{abstract}
ABSTRAK
Kebutuhan beton untuk struktur saat ini terus meningkat, sehingga menuntut perkembangan teknologi beton yang lebih baik. Salah satu jenis beton yang sering digunakan adalah beton ringan. Beton ringan dapat dibuat sebagai beton pracetak berbobot ringan sehingga dapat mempercepat pelaksanaan pembangunan dan mengurangi resiko kerusakan akibat gempa. Penelitian ini menggunakan beton styrofoam ringan dengan tulangan menyebar dan diteliti kapasitas lentur, kapasitas geser, keruntuhan, dan pola retak.Pada penelitian ini jumlah benda uji yang dibuat sebanyak 4 buah, 2 buah dengan dimensi $400 \mathrm{~mm} \times 400 \mathrm{~mm} \times 2000 \mathrm{~mm}$ dan 2 buah dengan dimensi $400 \mathrm{~mm}$ x $400 \mathrm{~mm} \times 2550 \mathrm{~mm}$. Semua benda uji menggunakan tulangan 8D16 yang disebar merata pada ke empat sisi tampang dan digunakan sengkang D10-200. Benda uji diletakkan pada loading frame yang kuat dan ditumpu sendi dan rol pada kedua ujungnya. Bentang bersih benda uji $1750 \mathrm{~mm}$ dan $2300 \mathrm{~mm}$, dan dibebani dengan satu titik pembebanan di tengah bentang. Pembebanan statik dilakukan secara bertahap sampai beban maksimum dengan menggunakan hydraulic jack. Kuat tekan silinder beton rata-rata $\left(\mathrm{f}_{\mathrm{c}}{ }^{\prime}\right)=1,59 \mathrm{MPa}$. Tegangan leleh rata-rata $\left(f_{y}\right)$ tulangan $\mathrm{D} 16=459 \mathrm{MPa}$, tegangan leleh rata-rata $\left(\mathrm{f}_{\mathrm{y}}\right)$ tulangan $\mathrm{D} 10=$ $331 \mathrm{MPa}$. Kapasitas momen nominal balok $\left(\mathrm{M}_{\mathrm{n}}\right)$, sesuai SNI tidak dapat digunakan. Dari hasil penelitian didapat bahwa perbandingan beban lentur teoritis metode pias dan beban geser metode SNI jauh lebih besar dari beban hasil pengujian, dan perbandingan beban teoritis geser metode SNI menggunakan faktor 0,3 hampir sama dengan beban hasil pengujian. Retak awal yang terjadi adalah retak lentur yang berupa retak halus disekitar tengah bentang, kemudian muncul retak dekat tumpuan dan retak ini terus merambat dan membesar menuju ke arah beban di daerah desak sehingga benda uji runtuh.
\end{abstract}

Kata kunci: Beton ringan, Styrofoam, Kapasitas lentur.

\begin{abstract}
Requirement of concrete for structure increase in recent years, that is need more concrete technology. One of the need technologies is the lightweight concrete. It produce in precast concrete with light in weight, it will accelerate the construction work, and reducing the risk of earthquake. This research using styrofoam in light weight concrete, with uniform reinforced and search of mechanical characteristic which are: flexure capacity, shear capacity, and crack. In this research work with four beams, two beams with dimension $400 \mathrm{~mm}$ x $400 \mathrm{~mm}$ x $2000 \mathrm{~mm}$ and another two beams has 400 $\mathrm{mm} \times 400 \mathrm{~mm} \times 2550 \mathrm{~mm}$. All of the beams using longitudinal reinforced 8D16, which are uniform at four sections, and transversal reinforced D10-200. The beam was set on strongly loading frame with simply supported. The net span beam were $1750 \mathrm{~mm}$ and $2300 \mathrm{~mm}$, and loading with one point load, at the middle of span. Static loading works in stages until reach maximum loading with hydraulic jack. Result from compression tests of concrete cylinder give average value of compression strength of concrete $\left(f_{c}{ }^{\prime}\right)=1,59 \mathrm{MPa}$. Average yield stress of deformed steel bar with diameter of $16 \mathrm{~mm}\left(f_{y}\right)$ was $=459 \mathrm{MPa}$, as for the $10 \mathrm{~mm}$ non deformed steel bars, the average of yield stress reaching 331 MPa. To analyze nominal moment capacity $\left(M_{n}\right)$, the calculation of SNI method is not relevant. The result reach ratio between load flexure theoretic in pale method and load shear calculation in SNI method larger then result of load tested. The beam shear capacity analysis using coefficient $(\alpha)=0.30$. The existing of initial crack is the flexure crack, which is smooth crack at the middle of span,
\end{abstract}


afterwards, crack turn up near by supported, it will continuous spreading to point of loading at pressure area, finally made the beam failure.

Keywords: Lightweight concrete, Styrofoam, Flexural capacity.

\section{PENDAHULUAN}

Kebutuhan beton untuk struktur saat ini terus meningkat, sehingga menuntut perkembangan teknologi beton yang lebih baik. Beton digunakan pada struktur berat dan struktur ringan seperti perumahan rakyat. Perumahan rakyat yang sudah ada saat ini masih kurang dan masih dibutuhkan pembangunan perumahan yang cukup banyak, seiring dengan bertambahnya jumlah penduduk.

Penggunaan beton ringan merupakan salah satu upaya untuk memenuhi kebutuhan perumahan tersebut, karena memungkinkan untuk dibuat sebagai beton pracetak yang ringan, cepat dalam pelaksanaan dan mengurangi resiko kerusakan akibat gempa.

Penelitian ini menggunakan balok beton styrofoam ringan dengan tulangan menyebar dan diteliti sifat mekanikanya serta kemungkinannya untuk diaplikasikan pada struktur ringan, khususnya untuk pembangunan rumah tinggal. Pemakaian styrofoam ini dipilih karena beton ringan styrofoam mempunyai berat sendiri yang relatif sangat ringan. Beton styrofoam yang diteliti pada penelitian ini dibuat dengan proporsi campuran $350 \mathrm{~kg}$ semen : $200 \mathrm{~kg}$ pasir : $15 \mathrm{~kg}$ styrofoam untuk $1 \mathrm{~m}^{3}$ beton, dan air sebanyak 157,5 liter dengan faktor air semen (fas) 0,45 .

Penelitian ini bertujuan untuk mengetahui kapasitas lentur, geser, dan pola retak balok beton styrofoam ringan dengan tulangan menyebar akibat beban statik. Tinjauan hanya dilakukan terhadap sifat teknis betonnya dan tidak dilakukan tinjauan ekonomis.

\section{TINJAUAN LITERATUR}

\subsection{Umum}

Salet (1990) melakukan penelitian tentang beton ringan dengan menggunakan foam yang mempunyai berat jenis $50 \mathrm{~kg} / \mathrm{m}^{3}$ dengan perbandingan campuran $340 \mathrm{~kg}$ semen : $70 \mathrm{~kg}$ pasir : 136 liter air dan $50 \mathrm{~kg}$ foam. Hasil yang didapat adalah workability betonnya tinggi dan menghasilkan kuat tekan beton 2,25 - 2,75 $\mathrm{MPa}$, kuat tarik 0,28 $\mathrm{MPa}$ dan modulus Young's $(E)=1506 \mathrm{MPa}$ dengan berat jenis sebesar $600 \mathrm{~kg} / \mathrm{m}^{3}$.

Hunaiti (1997) menggunakan foam (busa) neopore pada campuran mortar dengan perbandingan semen dan pasir $1: 3$ dengan faktor air semen 0,5 dan ditambah busa (foam) sebanyak $2 \%$ dari berat total campuran dan didapat kuat tekan pada umur 28 hari sebesar 12,11 MPa. 


\subsection{Beton Ringan}

Menurut Murdock dan Brook (1986), berat jenis beton ringan berkisar antara 1360 $1840 \mathrm{~kg} / \mathrm{m}^{3}$ dan berat jenis $1850 \mathrm{~kg} / \mathrm{m}^{3}$ dapat dianggap sebagai batas dari beton ringan yang sebenarnya, meskipun nilai ini kadang-kadang melebihi. Menurut Tjokrodimuljo (1997) beton disebut beton ringan jika beratnya kurang dari $1800 \mathrm{~kg} / \mathrm{m}^{3}$.

Menurut Winter dan Nilson (1993) beton ringan dibedakan dalam tiga kelompok yaitu: beton ringan sebagai penyekat, beton ringan sebagai bahan pengisi dan beton ringan untuk elemen struktur. Beton ringan yang digunakan untuk elemen struktur dikenal sebagai beton struktur beragregat ringan yang mempunyai kuat tekan lebih besar dari 17,5 MPa dan berat satuannya kurang dari $1800 \mathrm{~kg} / \mathrm{m}^{3}$. Sebagian besar beton ringan untuk struktur mempunyai berat antara $1500 \mathrm{~kg} / \mathrm{m}^{3}$ dan $1700 \mathrm{~kg} / \mathrm{m}^{3}$ dan kuat tekan rencana berkisar antara $20 \mathrm{MPa}$ sampai 27,5 MPa.

\subsection{Styrofoam}

Styrofoam termasuk dalam kategori polimer sintetik dengan berat molekul tinggi. Polimer sintetik berbahan baku monomer berbasis etilena yang berasal dari perengkahan minyak bumi. Styrofoam hanya sebuah nama dalam dunia perdagangan, nama sesungguhnya adalah polystyrene atau poli (feniletena) dalam bentuk foam. Feniletena atau styrene dapat dipolimerkan dengan menggunakan panas, sinar ultra violet, atau katalis. Poli (feniletena) merupakan bahan termo plastik yang bening (kecuali jika ditambahkan pewarna atau pengisi), dan dapat dilunakkan pada suhu sekitar $100^{\circ}$ C. Poli (feniletena) tahan terhadap asam, basa dan zat pengarat (korosif) lainnya, tetapi mudah larut dalam hidrokarbon aromatik dan berklor. Dalam propanon (aseton), poli (feniletena) hanya mengembang. Penyinaran dalam waktu yang lama oleh sinar ultra ungu, sinar putih, atau panas, sedikit mempengaruhi kekuatan dan ketahanan polimer terhadap panas. Poli (feniletena) berbusa atau styrofoam diperoleh dari pemanasan poli (feniletena) yang menyerap hidrokarbon volatil. Ketika dipanasi oleh kukus (steam) butiran akan melunak, dan penguapan hidrokarbon di dalam butiran akan menyebabkan butiran mengembang (Cowd, 1991).

\subsection{Lentur Pada Balok Beton Bertulang}

Balok beton bertulang dengan tampang segi empat apabila diberi beban yang ditambah berangsur-angsur mulai dari nol sampai balok hancur, maka ada tingkat perilaku yang berbeda. 
Pada beban kecil tegangan tarik maksimum beton lebih kecil dari modulus hancur, sehingga beton efektif mendukung tegangan tekan pada satu sisi dan tarik pada sisi yang lain. Tulangan juga mengalami tegangan tarik sama seperti beton. Pada kondisi ini tegangan yang terjadi pada beton kecil dan berbanding lurus dengan regangan yang terjadi. Distribusi tegangan dan regangan pada beton dan tulangan seperti ditunjukkan pada Gambar 1.c.

Penambahan beban mengakibatkan kuat tarik beton terlampaui dan mulai terjadi retak-retak akibat tarik. Retak-retak menjalar cepat ke atas sampai mendekati garis netral yang mengakibatkan letak garis netral bergeser ke atas diikuti dengan menjalarnya retakretak. Bentuk umum dan distribusi retak tarik ini diperlihatkan pada Gambar 1.d.

Retak-retak sangat mempengaruhi perilaku balok dalam mendukung beban. Pada tampang yang retak seperti tampang a-a pada Gambar 1.d, beton tidak lagi menyalurkan tegangan tarik sehingga tulangan harus menahan semua tegangan tarik yang terjadi. Tegangan dan regangan berbanding lurus sampai tegangan beton kurang lebih sebesar $0,5 f_{c}$ '. Distribusi tegangan dan regangan pada atau didekat tampang retak seperti ditunjukkan pada Gambar 1.e.

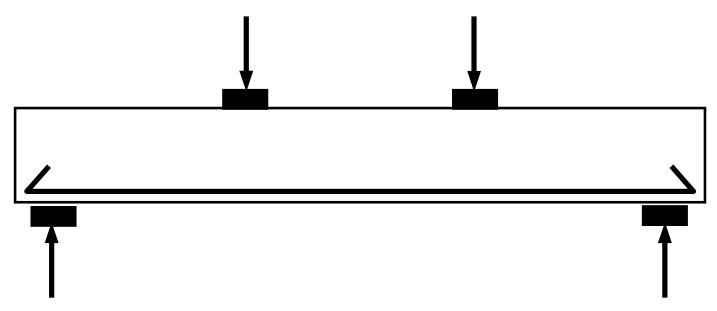

a. Kondisi balok pada beban kecil

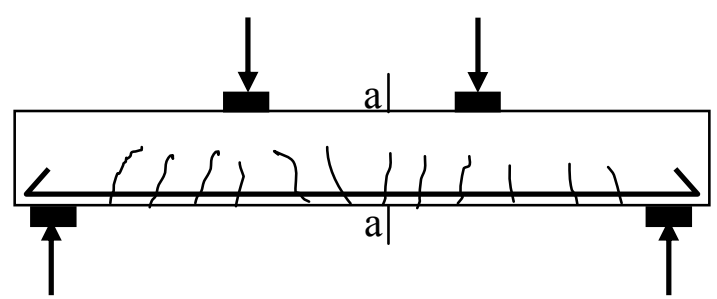

d. Retak-retak tarik akibat beban besar

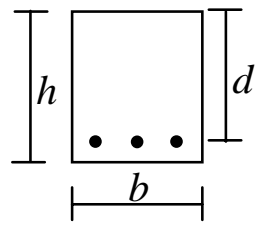

b. Tampang balok

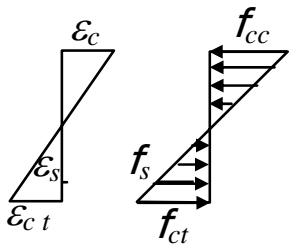

c. Regangan dan tegangan

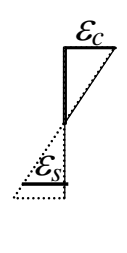

e. Regangan dan tegangan pada tampang retak
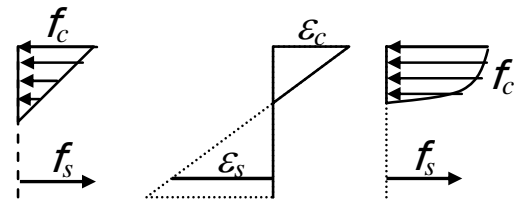

f. Regangan dan tegangan pada beban batas

\section{Gambar 1. Perilaku balok beton bertulang karena pembebanan yang bertambah besar secara berangsur-ansur (Winter dan Nilson,1993)}

Tegangan dan regangan akan naik dan hubungan antara keduanya tidak lagi berbanding lurus apabila beban masih terus ditambah. Distribusi tegangan beton pada daerah 
tekan mempunyai bentuk yang sama seperti grafik tegangan-regangan beton. Gambar 1.f menunjukkan distribusi tegangan dan regangan pada saat beban mendekati beban batas.

\subsection{Retak dan Ragam Keruntuhan Pada Balok Beton Bertulang}

Balok yang mempunyai proporsi dan tulangan yang baik, retak-retak tarik lentur akan terbentuk terlebih dahulu. Dengan adanya tulangan memanjang, lebar dan panjang retak tersebut hanya terjadi dalam ukuran yang kecil. Namun demikian apabila tegangan tarik diagonal pada ujung atas dari satu atau lebih retak-retak tersebut melampaui kekuatan tarik beton, retak tersebut akan berubah arah menjadi retak diagonal yang lebar dan panjangnya akan terus bertambah seperti ditunjukkan pada Gambar 2. Retak-retak ini dikenal sebagai retak geser lentur.

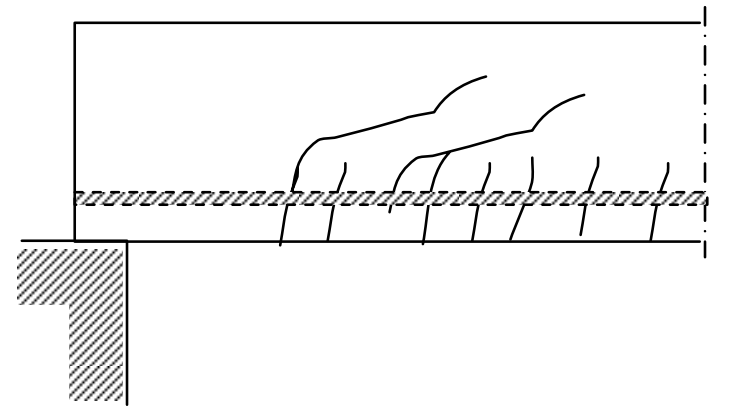

Gambar 2. Retak geser lentur (Winter dan Nilson,1993)

Retak diagonal sekali terbentuk kemungkinan akan menyebar dengan serentak pada saat itu juga atau pada saat adanya pembebanan sedikit lebih besar, dan memotong seluruh penampang balok dari tulangan tarik sampai ke permukaan tekan. Kemungkinan lain adalah retak akan menyebar menuju sebagian daerah tekan tetapi kemudian berhenti sebelum menembus ke permukaan tekan.

Menurut Nawy (1998) dapat terjadi tiga ragam keruntuhan atau kombinasinya yaitu:

1. keruntuhan lentur

2. keruntuhan tarik diagonal

3. keruntuhan tekan geser

Pada balok langsing cenderung terjadi ragam keruntuhan lentur seperti ditunjukkan pada Gambar 3.a. Pada daerah yang mengalami keruntuhan lentur, retak terutama terjadi pada sepertiga tengah bentang dan tegak lurus terhadap arah tegangan utama. Retak-retak ini diakibatkan oleh tegangan lentur $(f)$ yang sangat dominan yang besarnya hampir mendekati tegangan utama horizontal dan tegangan geser ( $v)$ yang sangat kecil. Apabila bebannya ditambah terus, retak-retak ini akan bertambah, dan retak awal yang sudah terjadi akan semakin lebar dan semakin panjang menuju sumbu netral penampang. Hal ini bersamaan 
dengan semakin besarnya lendutan di tengah bentang. Jika balok tersebut under reinforced, maka keruntuhan merupakan keruntuhan yang daktail (ductile) yang ditandai dengan lelehnya tulangan tarik. Perilaku daktail ini memberikan peringatan terlebih dahulu, sebelum terjadinya kehancuran total balok beton (collapse).

Keruntuhan tarik diagonal terjadi apabila kekuatan balok arah diagonal tarik lebih kecil dari kuat lenturnya seperti ditunjukkan pada Gambar 3.b. Retak-retak mulai terjadi di tengah bentang berarah vertikal yang berupa retak halus, dan diakibatkan oleh lentur. Retak ini diikuti oleh rusaknya lekatan antara baja tulangan dengan beton disekitarnya pada daerah perletakan. Tanpa adanya peringatan sebelum runtuh, 2 atau 3 retak diagonal terjadi pada jarak sekitar $1,5 d$ sampai $2 d$ dari muka perletakan. Untuk mencapai kesetabilan 1 retak diagonal ini melebar ke dalam retak tarik diagonal utama.

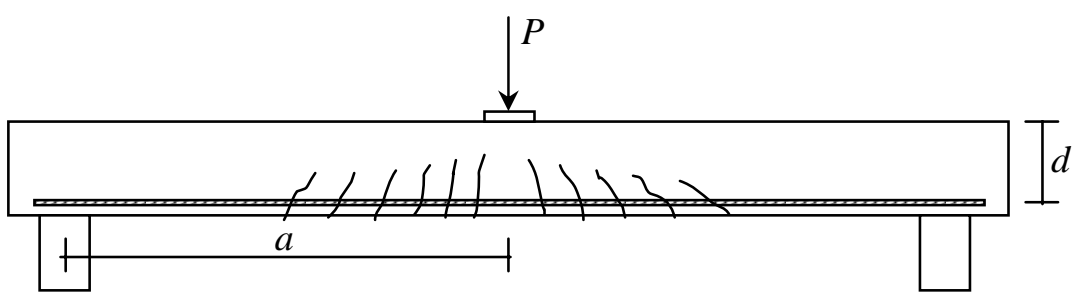

a. Keruntuhan lentur

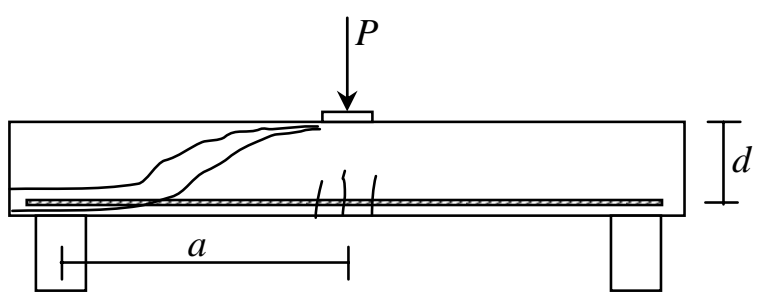

b. Keruntuhan tarik diagonal

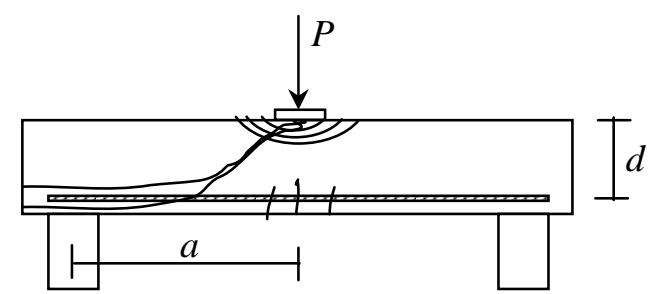

c. Keruntuhan tekan geser

\section{Gambar 3. Ragam keruntuhan balok (Nawy, 1998)}

Keruntuhan tekan geser dimulai dengan timbulnya retak lentur halus vertikal di tengah bentang dan tidak terus menjalar karena terjadinya hilangnya lekatan antara tulangan longitudinal dengan beton disekitarnya pada daerah perletakan, seperti ditunjukkan pada 
Gambar 3.c. Setelah itu diikuti dengan retak miring yang lebih curam dari retak tarik diagonal secara tiba-tiba, dan menjalar terus menuju sumbu netral. Kecepatan penjalaran ini semakin berkurang sebagai akibat dari hancurnya beton pada tepi tertekan dan terjadinya redistribusi tegangan pada daerah atas. Pada saat bertemunya retak miring dengan tepi beton yang tertekan, terjadilah keruntuhan secara tiba-tiba.

Pada Tabel 1. berikut ini diberikan ringkasan mengenai pengaruh kelangsingan balok dengan ragam keruntuhannya.

Tabel 1. Pengaruh kelangsingan balok terhadap ragam keruntuhan (Nawy, 1998)

\begin{tabular}{ccc}
\hline Kategori balok & Ragam keruntuhan & Kelangsingan $(a / d)$ \\
\hline Langsing & Lentur & $>5,5$ \\
Sedang & Tarik diagonal & $2,5-5,5$ \\
Tinggi & Tekan geser & $1,0-2,5$ \\
\hline
\end{tabular}

\section{CARA PENELITIAN}

\subsection{Benda Uji}

Pada penelitian ini jumlah benda uji 4 buah, seperti pada Tabel 2. dan Gambar 4.

Tabel 2. Ukuran dan tulangan benda uji

\begin{tabular}{cccccccc}
\hline No. & Kode & $\begin{array}{c}\text { Lebar } \\
(\mathrm{mm})\end{array}$ & $\begin{array}{c}\text { Tinggi } \\
(\mathrm{mm})\end{array}$ & $\begin{array}{c}\text { Panjang } \\
(\mathrm{mm})\end{array}$ & $\begin{array}{c}\text { Tulangan } \\
\text { Sengkang }\end{array}$ & $\begin{array}{c}\text { Jumlah } \\
\text { Tulangan }\end{array}$ & $\begin{array}{c}\text { Jenis } \\
\text { Pengujian }\end{array}$ \\
\hline 1 & LI1 & 400 & 400 & 2000 & D10-200 & $8 \mathrm{D} 16$ & Lentur \\
\hline 2 & LI2 & 400 & 400 & 2000 & D10-200 & $8 \mathrm{D} 16$ & Lentur \\
\hline 3 & LII1 & 400 & 400 & 2550 & D10-200 & $8 \mathrm{D} 16$ & Lentur \\
\hline 4 & LII2 & 400 & 400 & 2550 & D10-200 & $8 \mathrm{D} 16$ & Lentur \\
\hline
\end{tabular}
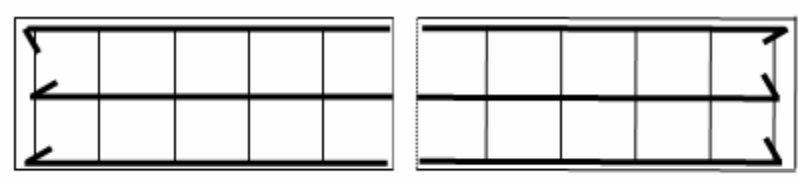

2000

(a). Benda uji LI1 dan LI2
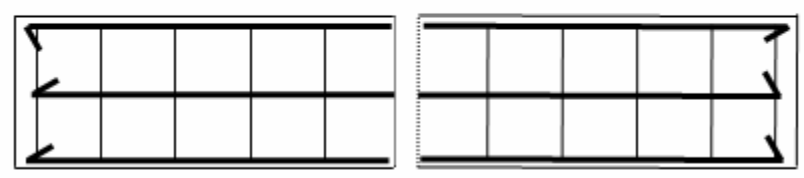

2550
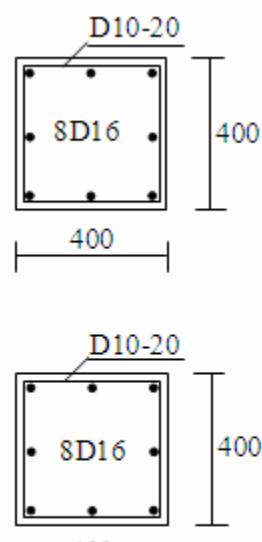

(b). Benda uji LII1 dan LII2

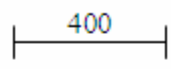

Gambar 4. Detail benda uji 


\subsection{Pengujian Benda Uji}

Pengujian dilakukan setelah benda uji berumur lebih dari 28 hari. Pengujian dilakukan dengan menempatkan benda uji pada loading frame dan dibebani tegak lurus sumbu benda uji dengan satu titik pembebanan di tengah bentang. Panjang bentang bersih benda uji lentur ada dua jenis yaitu $1,75 \mathrm{~m}$ dan 2,3 m, seperti ditunjukkan pada Gambar 5 .

Data yang akan didapat dalam pengujian lentur ini meliputi :

1. lendutan selama pembebanan berlangsung

2. besarnya beban pada saat terjadi retak

3. besarnya beban maksimum

4. pola retak

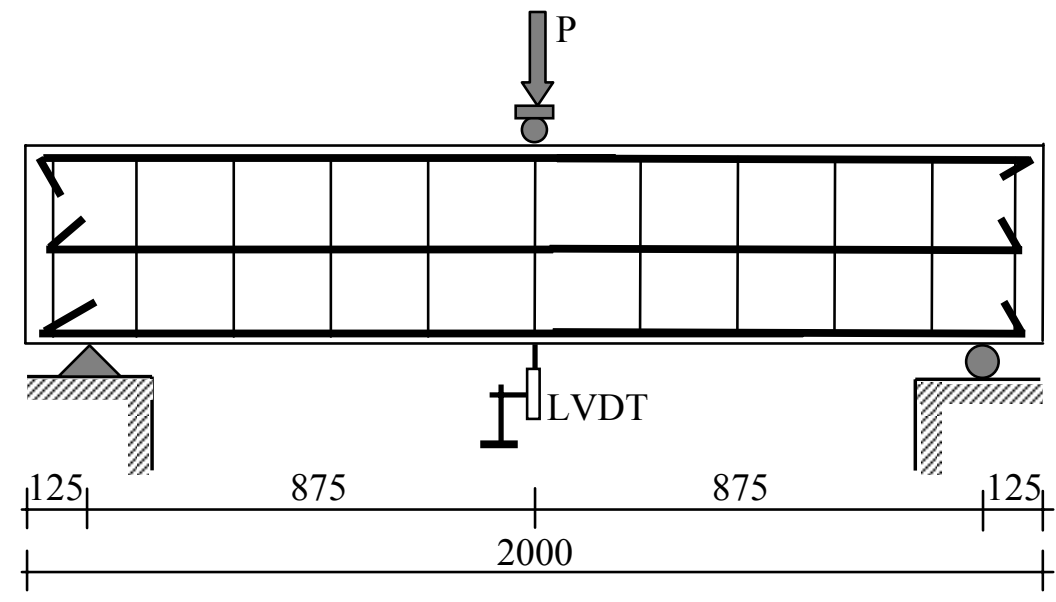

a. Set up pengujian LI1 dan LI2

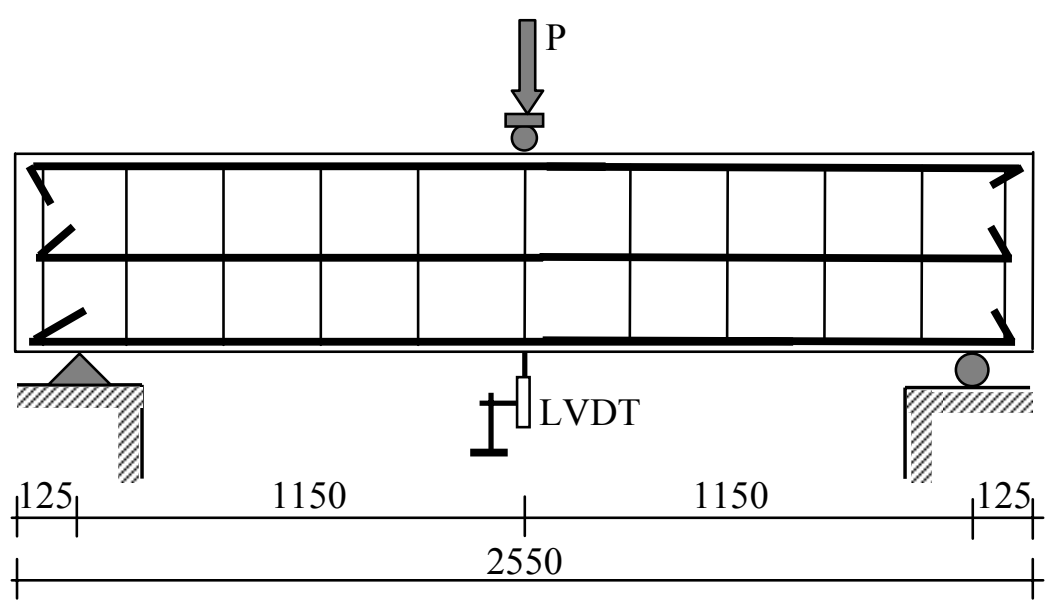

b. Set up pengujian LIII dan LII2

\section{Gambar 5. Set up pengujian}




\section{HASIL DAN PEMBAHASAN}

\subsection{Perhitungan Teoritis Kapasitas Lentur Benda Uji}

Perhitungan kapasitas lentur teoritis dengan metode pias dihitung berdasarkan luasan blok tegangan tekan beton, sesuai dengan bentuk diagram tegangan regangan beton hasil uji tekan silinder. Perhitungan kapasitas geser dihitung berdasarkan metode SNI. Kuat tekan rata-rata silinder beton dari hasil pengujian didapat sebesar 1,59 $\mathrm{MPa}$, tegangan leleh ratarata baja tulangan ulir D16 sebesar 459,31 MPa dengan modulus elastisitas rata-rata sebesar $199493 \mathrm{MPa}$, dan tegangan leleh rata-rata baja polos D10 sebesar $331 \mathrm{MPa}$. Untuk lebih jelasnya kapasitas benda uji hasil analisis metode pias seperti pada Tabel 3.

Tabel 3. Kapasitas benda uji hasil analisis metode pias

\begin{tabular}{ccccc}
\hline \multirow{2}{*}{ Kapasitas } & \multicolumn{4}{c}{ Benda Uji } \\
\cline { 2 - 5 } & LI1 & LI2 & LII1 & LII2 \\
\hline. $\mathrm{M}_{\mathrm{n}}(\mathrm{kNm})$ & 90,526 & 90,526 & 90,526 & 90,526 \\
\hline $\mathrm{V}_{\mathrm{n}}(\mathrm{kN})$ & 89,90 & 89,90 & 89,90 & 89,90 \\
\hline $\mathrm{P}_{\mathrm{Mn}}(\mathrm{kN})$ & 206,92 & 206,92 & 157,44 & 157,44 \\
\hline $\mathrm{P}_{\mathrm{Vn}}(\mathrm{kN})$ & 179,80 & 179,80 & 179,80 & 179,80 \\
\hline
\end{tabular}

Besar gaya $\mathrm{P}$ untuk benda uji LI1 dan LI2 agar terjadi runtuh lentur $\left(\mathrm{P}_{\mathrm{Mn}}=206,92\right.$ $\mathrm{kN})$ lebih tinggi dari gaya $\mathrm{P}$ agar terjadi runtuh geser $\left(\mathrm{P}_{\mathrm{Vn}}=179,80 \mathrm{kN}\right)$. Jadi secara teoritis benda uji LI1 dan LI2 akan gagal geser. Besarnya gaya P untuk benda uji LII1 dan LII2 agar terjadi runtuh lentur $\left(\mathrm{P}_{\mathrm{Mn}}=157,44 \mathrm{kN}\right)$ lebih rendah dari gaya $\mathrm{P}$ agar terjadi runtuh geser $\left(\mathrm{P}_{\mathrm{Vn}}=179,80 \mathrm{kN}\right)$. Jadi secara teoritis benda uji akan gagal lentur.

\subsection{Pengujian Lentur}

Hasil pengujian lentur beton styrofoam ringan dengan tulangan menyebar seperti ditunjukkan pada Tabel 4, Gambar 6, dan Gambar 7.

Tabel 4. Hasil pengujian lentur balok beton styrofoam

\begin{tabular}{|c|c|c|c|c|c|c|c|c|c|c|}
\hline \multirow[t]{3}{*}{ No. } & \multirow[t]{3}{*}{ Kode } & \multicolumn{3}{|c|}{ Dimensi } & \multirow{3}{*}{$\begin{array}{c}\text { Jarak } \\
\text { tump. } \\
(\mathrm{m})\end{array}$} & \multirow{3}{*}{$\begin{array}{c}\text { Jarak P } \\
\text { dari tump. } \\
\text { (m) }\end{array}$} & \multirow{2}{*}{\multicolumn{2}{|c|}{ Hasil Pengujian }} & \multirow{2}{*}{\multicolumn{2}{|c|}{$\begin{array}{c}\text { Lendutan yang } \\
\text { terjadi saat }\end{array}$}} \\
\hline & & \multirow{2}{*}{$\begin{array}{l}\text { Lebar } \\
(\mathrm{mm})\end{array}$} & \multirow{2}{*}{$\begin{array}{l}\text { Tinggi } \\
(\mathrm{mm})\end{array}$} & \multirow{2}{*}{$\begin{array}{l}\text { Panjang } \\
(\mathrm{mm})\end{array}$} & & & & & & \\
\hline & & & & & & & $\begin{array}{c}P_{\text {Retak I }} \\
(\mathrm{kN})\end{array}$ & $\begin{array}{l}P_{\text {Maks }} \\
(\mathrm{kN})\end{array}$ & $\begin{array}{c}\mathrm{P}_{\text {Retak I }} \\
(\mathrm{mm})\end{array}$ & $\begin{array}{l}P_{\text {Maks }} \\
(\mathrm{mm}) \\
\end{array}$ \\
\hline 1 & LI1 & 400 & 400 & 2000 & 1,75 & 0,875 & - & 71,16 & - & 9,11 \\
\hline 2 & LI2 & 400 & 400 & 2000 & 1,75 & 0,875 & 24,78 & 70,48 & 2,80 & 9,32 \\
\hline 3 & LII1 & 400 & 400 & 2550 & 2,30 & 1,150 & 45,30 & 82,60 & 7,74 & 15,89 \\
\hline 4 & LII2 & 400 & 400 & 2550 & 2,30 & 1,150 & 20,81 & 37,21 & 5,25 & 9,38 \\
\hline
\end{tabular}




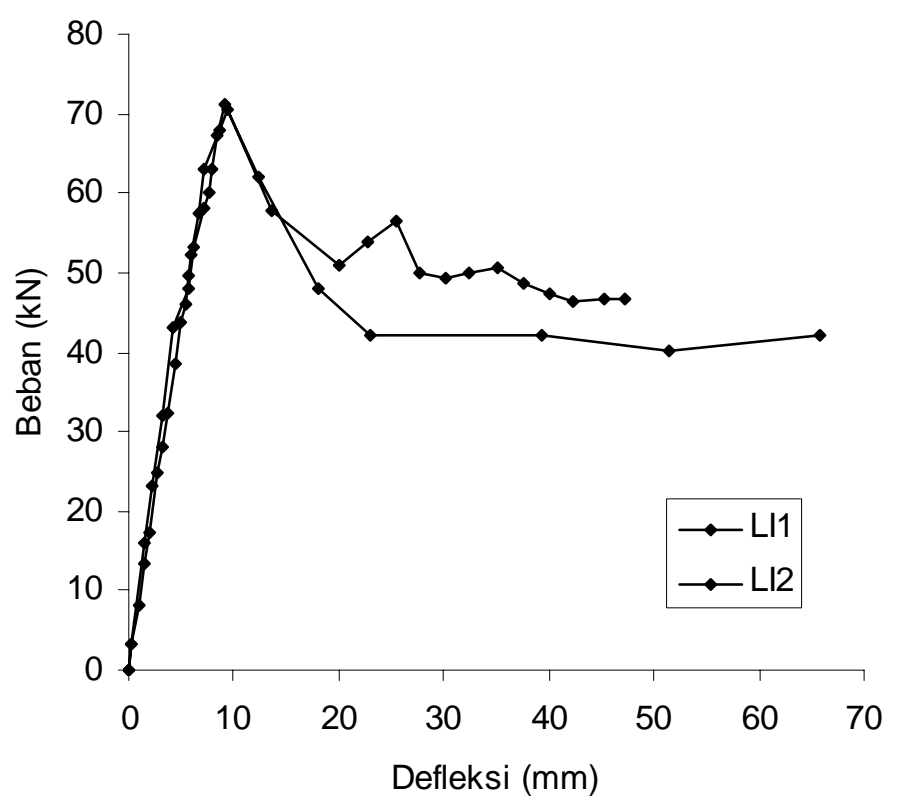

Gambar 6. Hubungan beban dengan defleksi benda uji LI1 dan LI2

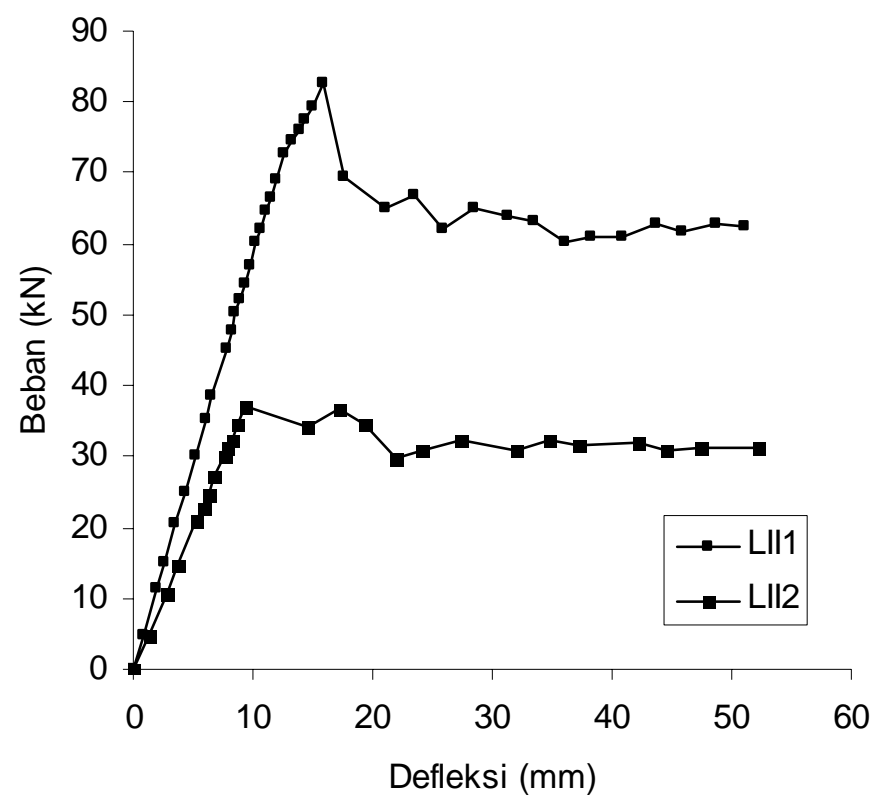

Gambar 7. Hubungan beban dengan defleksi benda uji LII1 dan LII2

\subsection{Perbandingan Hasil Analisis Teoritis dan Pengujian}

Perbandingan beban lentur teoritis metode pias dan beban geser berdasarkan SNI (Tabel 3) dengan beban pengujian (Tabel 4) seperti pada Tabel 5. Dari Tabel 5 dapat dilihat bahwa beban balok hasil pengujian jauh di bawah beban teoritis, karena terjadi keruntuhan geser. Rumus geser dengan koefisien $\alpha=0,75$ untuk beton ringan tidak sesuai untuk beton 
styrofoam karena hasilnya jauh lebih besar dari hasil pengujian. Untuk perhitungan kapasitas geser beton styrofoam harus dicari besarnya koefisien $\alpha$ yang sesuai.

Tabel 5. Perbandingan hasil analisis teoritis dan pengujian

\begin{tabular}{|c|c|c|c|c|c|}
\hline \multirow{2}{*}{$\begin{array}{l}\text { Benda } \\
\text { Uji }\end{array}$} & \multicolumn{2}{|c|}{ Teoritis } & \multirow{2}{*}{$\begin{array}{c}\text { Pengujian } \\
\begin{array}{c}P_{\text {maks }} \\
(\mathrm{kN})\end{array}\end{array}$} & \multicolumn{2}{|c|}{ Pengujian/Teoritis } \\
\hline & $\begin{array}{c}\mathrm{P}_{\text {Lentur }} \\
\text { (metode pias) } \\
(\mathrm{kN}) \\
\end{array}$ & $\begin{array}{c}\mathrm{P}_{\text {Geser }} \\
(\text { metode SNI) } \\
(\mathrm{kN}) \\
\end{array}$ & & $\begin{array}{c}\mathrm{P}_{\text {maks }} / \mathrm{P}_{\text {lentur }} \\
(\%)\end{array}$ & $\begin{array}{c}\mathrm{P}_{\text {maks }} / \mathrm{P}_{\text {geser }} \\
(\%)\end{array}$ \\
\hline LI1 & 206,92 & 179,80 & 71,16 & 34,39 & 39,58 \\
\hline LI2 & 206,92 & 179,80 & 70,48 & 34,06 & 39,20 \\
\hline LII1 & 157,44 & 179,80 & 82,60 & 52,46 & 45,94 \\
\hline LII2 & 157,44 & 179,80 & 37,21 & 23,63 & 20,70 \\
\hline \multicolumn{6}{|c|}{$V_{c}=\alpha \frac{1}{6} \sqrt{f_{c}^{\prime} b_{w}} d$} \\
\hline \multicolumn{6}{|c|}{$V_{s \text { maks }}=\alpha \frac{2}{3} \sqrt{f_{c}{ }^{\prime}} b_{w} d$} \\
\hline$V_{n}=$ & $V_{c}+V_{s m a k s}$ & $\alpha\left(\frac{5}{6} \sqrt{f_{c}{ }^{\prime} b}\right.$ & $=\alpha\left(\frac{5}{6} \sqrt{1}\right.$ & 400)(285.2) & )$=11$ \\
\hline
\end{tabular}

Kebutuhan gaya $\mathrm{P}$ untuk geser balok $\left(\mathrm{P}_{\mathrm{Vn}}\right)$ :

$$
\begin{aligned}
1 / 2 \mathrm{P}_{\mathrm{Vn}} & =\mathrm{V}_{\mathrm{n}} \\
\mathrm{P}_{\mathrm{Vn}} & =2 \mathrm{~V}_{\mathrm{n}} \\
& =2(119,87 \alpha)=239,74 \alpha
\end{aligned}
$$

Jadi besarnya koefisien $\alpha$ yang sesuai untuk geser beton styrofoam dihitung dengan persamaan berikut ini:

$$
\alpha=\frac{P_{\text {pengujian }}}{239,74}
$$

Besarnya koefisien $\alpha$ seperti pada Tabel 6.

Tabel 6. Koefisien $\alpha$ untuk perhitungan kapasitas geser beton styrofoam

\begin{tabular}{cccc}
\hline Benda uji & $\begin{array}{c}\mathrm{P}_{\text {maks pengujian }} \\
(\mathrm{kN})\end{array}$ & $\alpha$ & $\begin{array}{c}\alpha_{\text {rata- }} \\
\text { rata }\end{array}$ \\
\hline LI1 & 71,16 & 0,30 & 0,27 \\
\cline { 1 - 3 } LI2 & 70,48 & 0,29 & \\
\cline { 1 - 3 } LII1 & 82,60 & 0,34 & \\
\cline { 1 - 3 } LII2 & 37,21 & 0,16 & \\
\hline
\end{tabular}


Dari Tabel 6 koefisien $\alpha_{\text {rata-rata }}$ untuk perhitungan kapasitas geser beton styrofoam adalah 0,27 , tetapi karena nilai $\alpha$ yang didapat untuk benda uji LII2 jauh lebih kecil dari nilai $\alpha$ untuk benda uji LI1, LI2 dan LII1 maka nilai $\alpha$ yang disarankan diambil dari nilai rata-rata LI1, LI2 dan LII1 sebesar 0,3. Dengan menggunakan koefisien $\alpha=0,3$ maka kebutuhan gaya $\mathrm{P}$ untuk geser $\left(\mathrm{P}_{\mathrm{V}_{\mathrm{n}}}\right)$ adalah sebagai berikut:

$$
\mathrm{P}_{\mathrm{Vn}}=239,74 \alpha=239,74.0,3=71,92 \mathrm{kN}
$$

Perbandingan hasil analisis geser teoritis berdasarkan SNI menggunakan koefisien $\alpha=0,3$ dengan hasil pengujian diperoleh hasil seperti pada Tabel 7.

Tabel 7. Perbandingan beban teoritis geser SNI $(\alpha=0,3)$ dengan beban pengujian

\begin{tabular}{cccc}
\hline Benda uji & $\begin{array}{c}\mathrm{P}_{\text {maks pengujian }} \\
(\mathrm{kN})\end{array}$ & $\begin{array}{c}\mathrm{P}_{\text {teoritis SNI }} \\
(\alpha=0,3)\end{array}$ & $\begin{array}{c}\text { Pengujian/Teoritis } \\
(\%)\end{array}$ \\
\hline LI1 & 71,16 & 71,92 & 98,94 \\
\hline LI2 & 70,48 & 71,92 & 98,00 \\
\hline LII1 & 82,60 & 71,92 & 114,85 \\
\hline LII2 & 37,21 & 71,92 & 51,74 \\
\hline
\end{tabular}

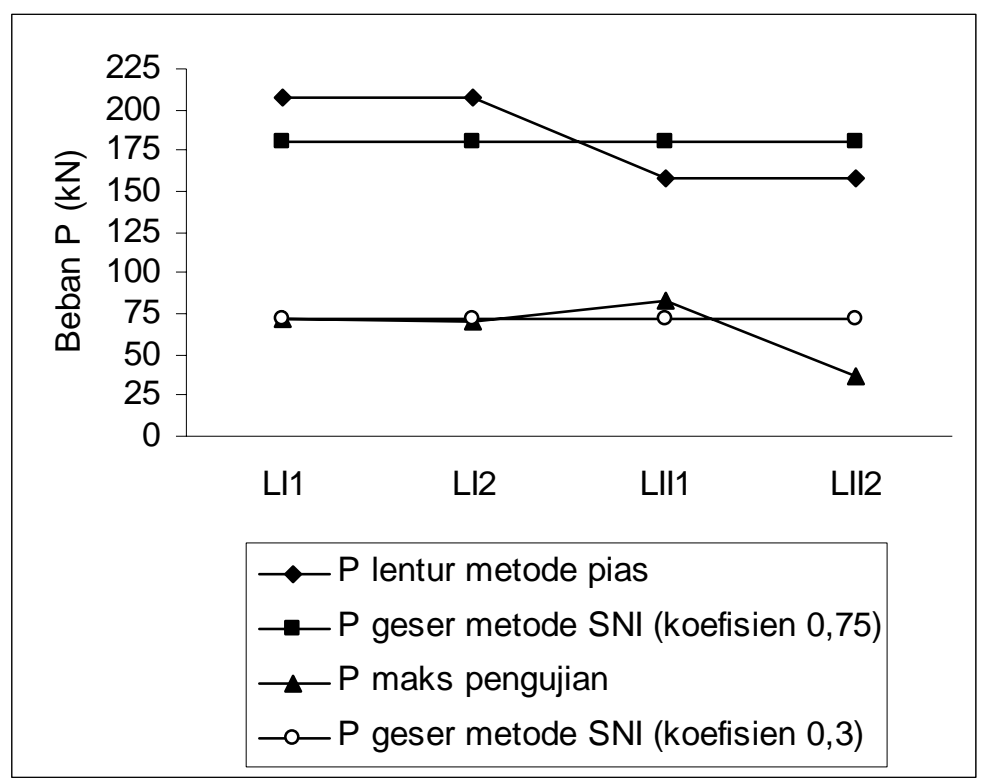

Gambar 8. Perbandingan beban (P)

\subsection{Pola Retak}

Retak awal yang terjadi adalah retak lentur yang berupa retak halus disekitar tengah bentang, kemudian muncul retak dekat tumpuan dan retak ini terus merambat dan membesar 
menuju ke arah beban di daerah desak dan benda uji runtuh. Untuk lebih jelasnya dapat dilihat pada Gambar 9.

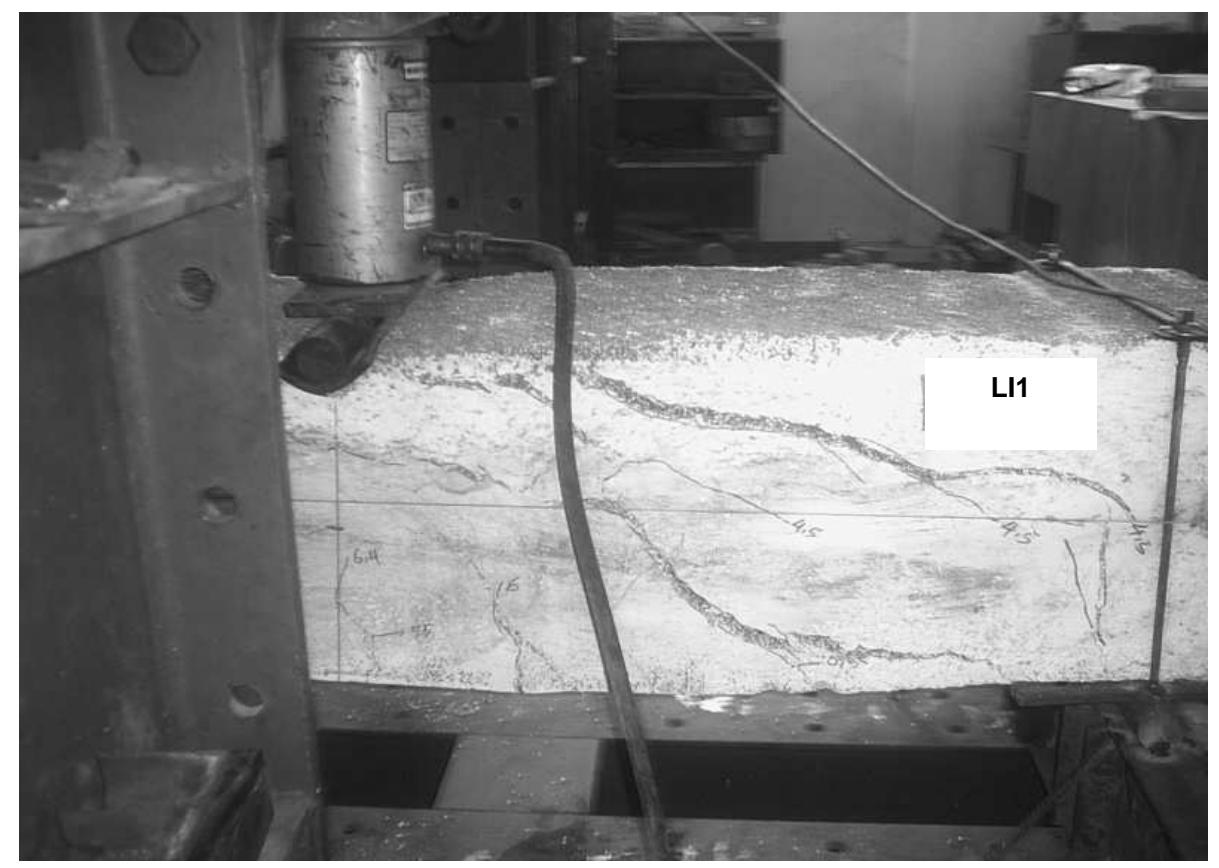

Gambar 9. Pola retak

\section{KESIMPULAN}

1. Beban lentur teoritis metode pias dan beban geser teoritis berdasarkan SNI jauh lebih besar dari beban hasil pengujian

2. Perhitungan kapasitas geser berdasarkan SNI dapat dipakai untuk beton styrofoam dengan menggunakan koefisien $\alpha=0,3$

3. Retak awal yang terjadi adalah retak lentur yang berupa retak halus disekitar tengah bentang, kemudian muncul retak dekat tumpuan dan retak ini terus merambat dan membesar menuju ke arah beban di daerah desak sehingga benda uji runtuh

\section{PUSTAKA}

1. Cowd, M.A., (1991). Kimia Polimer, Penerbit ITB, Bandung

2. Hunaiti, Y.M., (1997). Composite Action of Foamed and Lightweight Aggregate Concrete, Journal of Material in Civil Engineering, August 1996, pp 111 - 113,

3. Murdock, L.J. dan Brook, K.M., (1986). Bahan dan Praktek Beton, edisi ke-4, Erlangga, Jakarta

4. Nawy, Edward G., (1998). Beton Bertulang suatu Pendekatan Dasar, Cetakan II, PT Refika Aditama, Bandung, 
5. Salet, T.A.M., (1990). Struktur Analisis of Sandwich Beam Composed of Reinforced Concrete Faces and a Foamed Concrete Core, Desertation, Univercity Eindhoven, Belanda

6. Tjokrodimuljo, K., (1996). Teknologi Beton, Nafiri, Yogyakarta

7. Winter, G. dan Nilson, Arthur H., (1993). Perencanaan Struktur Beton Bertulang, PT. Pradnya Paramita, Jakarta. 